\title{
Evolution of Smart Classroom Concept Integrated with Smart Devices
}

\author{
Amogha Revanasiddappa Badami ${ }^{1}$, Dhanush $\mathbf{N}^{1}$, Arjun $\mathbf{T}^{1}$, Hitesh Kumar $\mathbf{P}^{\mathbf{1}}$, Mr Jayanth $\mathbf{C}^{\mathbf{2}}$ \\ ${ }^{2}$ Assistant Professor, ${ }^{1,2}$ Department of Telecommunication, Dayananda Sagar College of Engineering, \\ Bangalore, Karnataka, India
}

\begin{abstract}
In olden days teaching was going in a traditional way. And then it gave way to E-learning. Here computers, projectors and laptops were used for teaching. Then evolved M-learning i.e., Mobile learning. This is a trending tremendous technology nowadays where students use smart phone for learning. This project involves research and survey to identify how usage of smart class rooms at education institutions can be made under the control of authorities and how 1000's of lecture hours can be saved in a year using this techniques. As the students were misusing their phones new techniques called U- learning and NUlearning were developed where lot of sensors were involved to control the miss-usage of smart phones.
\end{abstract}

Keywords: Smart classroom, Smartphone, Mobile learning, Collaborative learning, Near field communication

\section{INTRODUCTION}

Nowadays the use of new way of teaching such as collaborated learning needs to be revolutionized from a traditional classroom to the modern active style. The students should share resources and discuss with each other through electronic devices. The design of smart classroom style of learning will enable us to get control over projectors, interactive whiteboards and other classroom equipment's in order to enhance interaction between teachers and students.

Students use Smart devices like Smart phones, ipad and tablet computers for gaining knowledge. Using these devices information can be accessed anywhere and anytime via internet. Even attendance can be taken using smart phones in the educational institutions which saves a lot of time and increases lecture hours using a mobile application. Also students can carry their textbooks and other study materials through these devices and can access whenever required. Inspite of many advantages Educational institutions are not permitting the use of these devices inside the campus as students get addicted to these devices and loose concentration in their studies. Breaking these rules is very easy but following a rule is the difficult part for the students. But, if we force them to follow the rules, it may distract the students from their studies. Rules shouldn't be imposed on students but rules should be in such a way that the students must follow it unintentionally and purposefully. Authorities can configure the list of white listed applications students can use in their phones when they are inside the campus. So that they can block the usage of unwanted applications.

\section{LITERATURE SURVEY}

Mahesh G, Jayahari KR, and Kamal Bijlani [1], In the field of education smart phones play a vital role. Smart phones are used to take pictures of important notes and also softcopy of notes. Also information can be gained by searching in the internet. This paper proposes a mobile application which helps educational institutions to control the students. Attendance can also be taken using the same application which saves a lot of lecture time. This will also reduce the chances of students marking proxy attendances. Even though smart phones have all these 
advantages, mobile phones are banned in many institutions as the students misuse their phones during the class hours by playing games and by chatting with friends.

There are many advantages of smart phones if permitted to use in classrooms. Students will be familiar with the usage of smart phones which helps in future. They learn about new trends and technologies easily. Learning will be up to date. Old method of searching for books or going to library, book bank will be completely reduced. And also, students will get information about latest trends and technologies without help of a lecturer.

Students will be aware of new technologies not only in classrooms, but also from home too. So gaining of knowledge is possible anywhere, anytime. Students can learn together by discussing with each other through internet which is nothing but combined study. Nowadays 'Computer supported collaborative learning' (CSCL) plays a vital role in learning. Using smart phone we can introduce a new term called 'Smartphone supported collaborative learning' (SSCL) where students can learn collaboratively using smart phone.

The main reasons for not allowing mobile phones in educational institutions are as follows. Students get addicted to mobile games. They continuously text with their friends during class hours as shown in the fig 1. When the phone rings entire class will be distracted. Smartphone also allows students to cheat during exams.

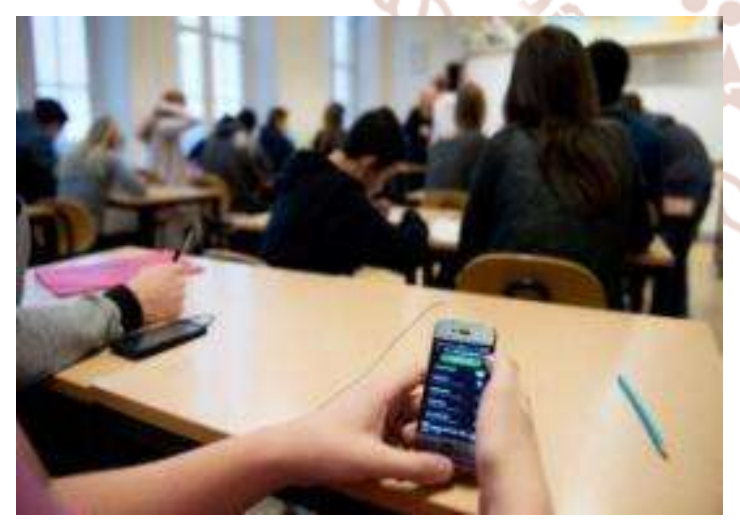

Fig1. Students using Mobile phone during lectures

Many educational institutions are not positively supporting the implementation of multimedia classrooms due to many problems. Teachers generally need to arrive classroom 5-10 minutes early to start the equipments like projector, computer, screen etc, if one of the systems fails, it affects the whole class and funding is another problem. This problem can be solved using a central controller. Once the teacher arrives, he can directly start the class and thus the lecture time can be increased.

In collaborative learning student-teacher interaction was not allowed. To overcome this problem a hardware device called gateway was introduced which controls all the functionalities. To reduce the time of taking attendance, a webcam was introduced which automatically recognizes the face and automatically attendance will be recorded. The same feature can be provided through the smart phone application called high level architecture of the system which is show in fig2. When students take their selfie-photos, the app sends them to the server through the Wi-Fi router. These photos are sent to the face recognition service, which is Face++ now for matching it with the registered ones which are stored at the time of student registration. Face recognition service provides back the response whether the photos match or not, which is stored in the main database along with the selfiephoto for future references/audits. Server provides a response back to the client mobile app mentioning whether the matching was success or not, if the photos were not matched, student will have to try giving attendance again.

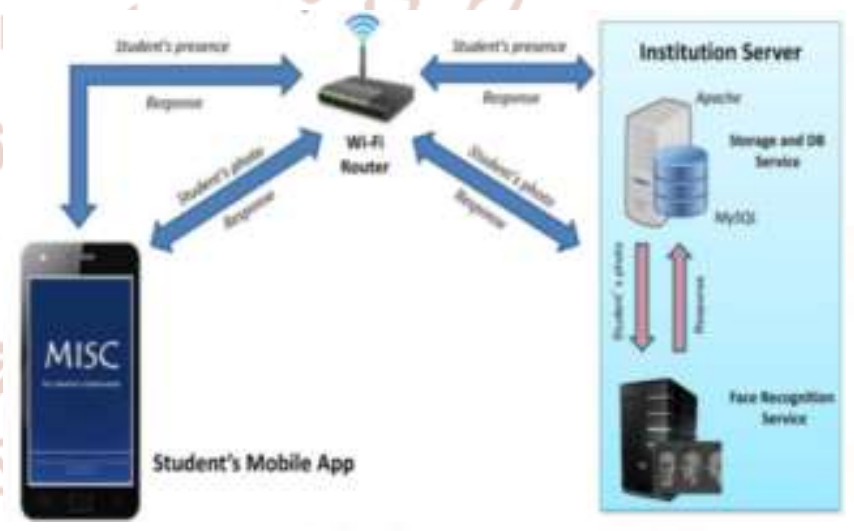

Fig2. High level architecture of the system

Almost $72 \%$ people are supporting to use mobiles in educational institutions. And $28 \%$ are not supporting due to the above mentioned reasons. So if we can overcome these disadvantages then everyone will support to use mobile phones in classrooms.

Wei Hsun Lee, Ming Chieh Kuo, Chung Chieh Hsu [2], In the past we used to have the traditional way of teaching, and then it got evolved to E-learning, where computers were involved in teaching-learning process. Then came the era of M-learning, where 
mobiles were involved. One could easily access the information from anywhere and anytime unless the device had internet connection. This got updated to the U-learning. Here lot of sensors were involved which works on-above the M-learning technology.

Then came the concept which emphasised towards smart class is done on the Student-Teacher interaction. Having this in concern the whole paper utilises the concept of Near Field Communication (NFC) and an App to be installed in mobile to utilise this technology. Near Field Communication is the technique of establishing the communication between any two devices by bringing them near to each other and the App controlling it is the NULP App (NFCbased interactive and ubiquitous learning platform App). The distance has to be maintained is around $4 \mathrm{cms}$. This technology can find the applications in the digital payments, electronic ticket smart-cards etc. So student having a NFC enabled phone, can contribute to "an In-classroom Interactive Learning Platform by Near Field Communication". This system is the Interactive way of learning and teaching technique implemented in any classroom. There are 4 ways to achieve it, interactive teaching, gradual learning, dynamic grouping, and creative teaching materials designs.

The interactive teaching is designed to complement the traditional way of learning. The teacher will previously label the NFC tags as the A,B,C,D etc.

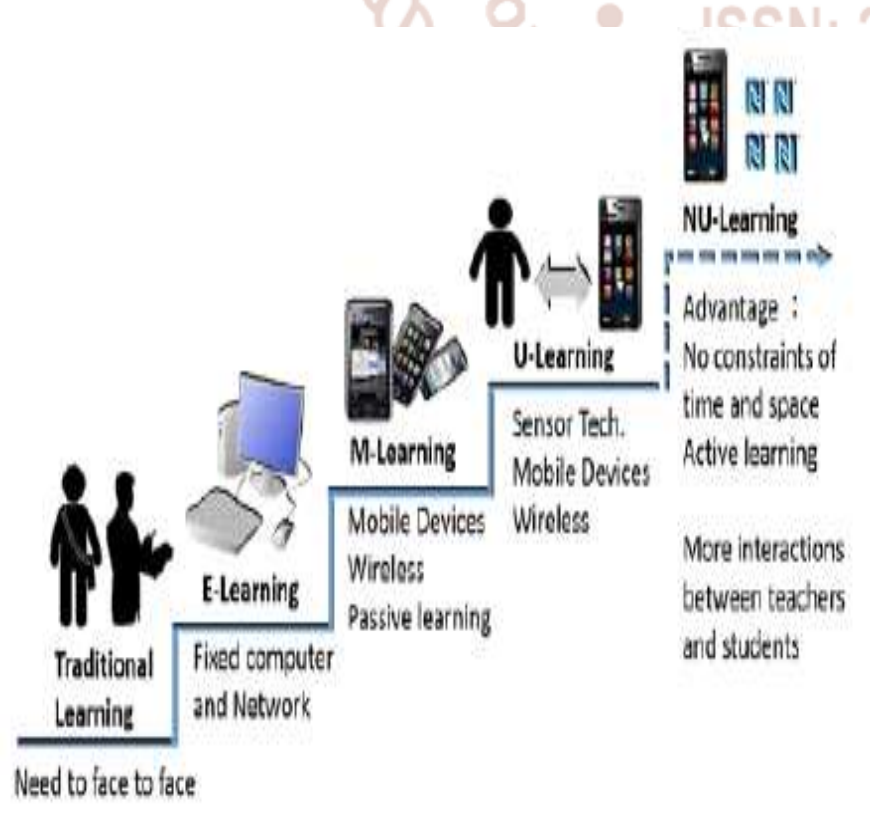

Fig 3. Paradigm shifts in e-Learning

Once the student settles down and tap the NFC tags through their mobile, it'll update the student's information using the help of the NULP App. This information will be updated in the teacher's computer, considering the student's mobile and the teacher's computer will be connected to the same Wi-Fi. Gradual learning can be achieved by solving the Assignments. The Assignments will have more specific tasks to carry on. To select any task there appears to be two options in the NULP App, create and return. By selecting create, a task gets created. Once the tasks are completed, the App will update the status in the teacher's computer. By this way a student will be learn gradually.

Having not involved in grouping and discussion between the students in teaching, it just won't contribute to the interactive learning platform. So there comes another feature of NULP App. It involves Dynamic grouping of students. This feature groups the students randomly and chooses a leader out of it. By doing this it saves most of time which would have been wasted if done manually. The App also lets the teacher to know about the groups and their respective leaders. Creative teaching materials designs lets the teacher to decide and design the set of tasks that student will perform. The teacher will have the freedom to teach by his own way, by customising the study materials or URL to be shared among students. The students have to touch the tags and the shared materials will be available for them to work on. This increases the effectiveness of the learning process.

Going through the eras of the classroom teaching techniques employed during ages, overcoming the disadvantages of all the teaching technique levels discussed above. We got to learn the benefits of the NULP App, and how it contributes towards the smart classroom.

\section{Disadvantages:}

(a) Not scalable: With the classroom strength being too high providing an NFC tags for each and every student is not possible.

(b) All students can't afford a NFC enabled phones, as NFC is a premium feature which comes in premium smart phones only.

Ramesh Guntha, Balaji Hariharan, P. Venkat Rangan [3], In smart class room echo cancellation place important role in transmitting and receiving information. Through this method it provides quality clear audio for communication. The echo cancellation method is done by sending the audio signals to the 
personal computer. The echo cancellation method is demonstrated through gaze technique, where it requires personal computers and high definition cameras. Echo cancellation method is done by splitting and processing of audio from the speaker and later compare with the required audio and remove the similar echo causing audio.

In gaze technique, it shows that different angles of the students and lecturer. The different angle videos are given to separate Personal computers where only required video is played at the other classroom where it is like video conference and it make sure its coming under gaze technique. Audio format is also the same as mentioned above. In mode talk method the lecturer will be teaching without being interrupted, if any students at different classroom has doubt he make an indication where the lecturer identify and activate only the student located classroom mics.

There are three important techniques for echo cancellation. There are as follows:-

central audio 2) mode talk 3) hand held talk

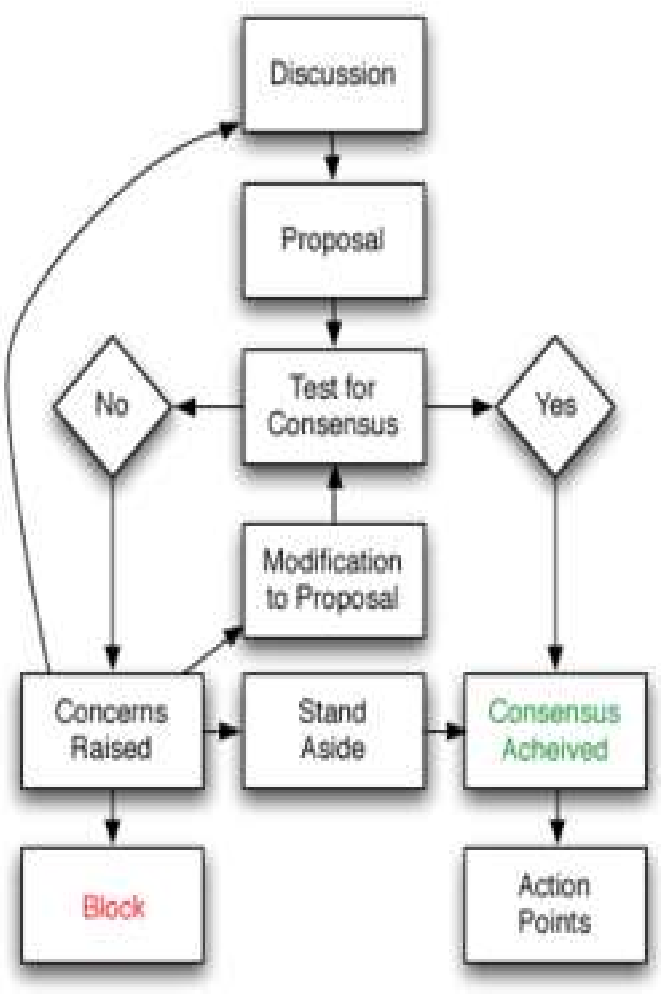

Throughout this paper we brief about smart classrooms, where we try to overcome echo generated by echo cancellation method, also we have discussed about the three important echo cancellation methods, advantages and disadvantages, feedbacks. Further for the betterment of smart classrooms troubleshooting of similar problems are done

\section{Advantages:}

It allows anyone to talk freely or hands free where no need to talk from a particular place. No permission is required for students to talk or get their questions clarified.

\section{Disadvantages:}

From central audio method confusion will be created as where to look since audio will be coming from different directions. Mode talk method make the students wait until the teacher is ready to clarify students doubts and questions. After conducting feedback session from the students, they did not like this echo cancellation technique since the audio used to come from different places. This method cannot be used for meeting and conference modes where the user has to wait to get attention of the teacher.

\section{Ubiquitous classroom architecture:}

Hichem Bargaoui, Rawia Bdiwi [4], It consists of hardware and software designs. the hardware design which includes 3 major components: the information system, the embedded gateway and the smart devices. The first component is the information system: it contains the administration tools and the database server. Its goals are user management, remote management of multiple classrooms and remote security management. The second component is the embedded gateway, which enable bridging multiple classrooms, remote access and data exchange with smart devices. Finally, the third component is the smart devices and sensors. The student and the teacher can interact with these devices such as smart board, computer, interactive response system, video and audio devices. The software design includes the middleware for ubiquitous classroom. The foremost objective of the gateway is to manage classroom devices, interconnect the classroom with the Internet. The middleware offer possibility to execute application and add devices. When designing the middleware, we took into account the following design issues: the remote integration of application, remote Classroom management, automatic device detection and connectivity. 


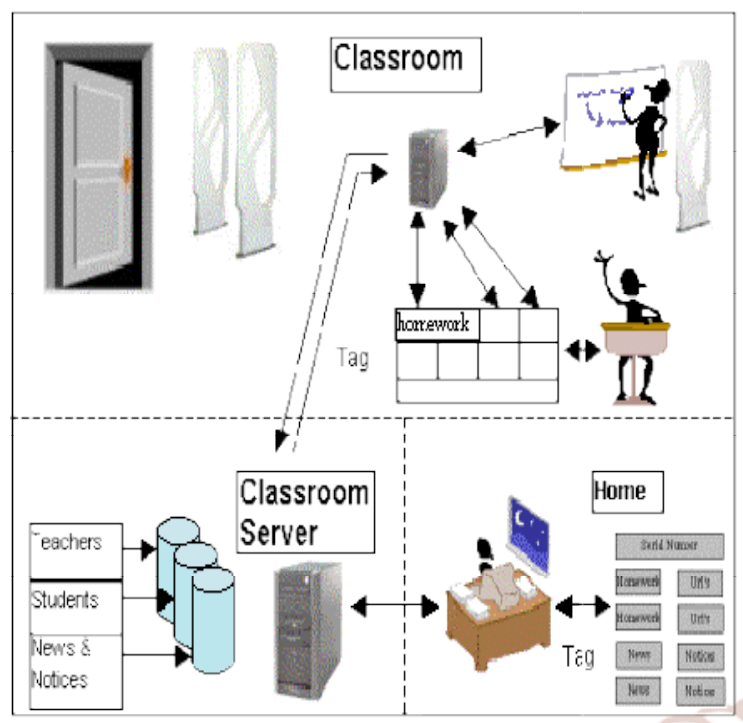

Fig 5. Ubiquitous classroom architecture

Ubiquitous classroom architecture enables teacher and students to have interactional classroom where several devices are connecting through this gateway. Also, it applies ambient intelligence to support teaching and learning. The current design and implementation of the solution are still in progress as a lot of issues are to be resolved related to the architecture for its global form. These issues are mainly related to privacy in ubiquitous computing and security: Student may take control of the classroom. And also the cost pertaining to the infrastructure of these classrooms are taken into account.

Raviprakash Shriwas ,Nikesh Patel, Asif Bherani, Arti Khajone, Manish Raut [5], In a country like INDIA, Catering industries are the most evolving industry ever. In many local restaurants, they follow the traditional way of ordering food, first the customer select the desired food, then waits for the waiter to take the order, in-between if the customer is a foodie, he asks for the reviews and opinions of the waiter. After all these time-consuming steps are done, waiter places the order. Another well known method of placing order followed by local restaurants is "SelfService". This is one kind of fast methods of ordering food. But not all restaurants can adapt to this method as it takes out the luxury feel. Then came a highly developed, communicative modules, Zigbee based systems. This was preferred for node to node communications only and are not scalable.

So the proposed system utilises the communication technology to order the food by killing the time delay it takes for a traditional way and which can be scalable to any type of restaurants. So it comes down to an idea of Touch-screen based ordering system, where it uses a Touch-screen, Micro-Controller, RF modules. The whole concept comes in a set of modules:

\section{(a) Transmitter Block:}

It consists of an input module and an output module. Here the input module consists of a Touch-screen, which displays the food items, variety of dishes under different category including the price of that item and takes the order by a simple touch. Once food is selected, it places the order. It places the order using the help of output module, i.e. the RF module. More specifically it uses the Transmitter module. The processing is done by the Micro-Controller.

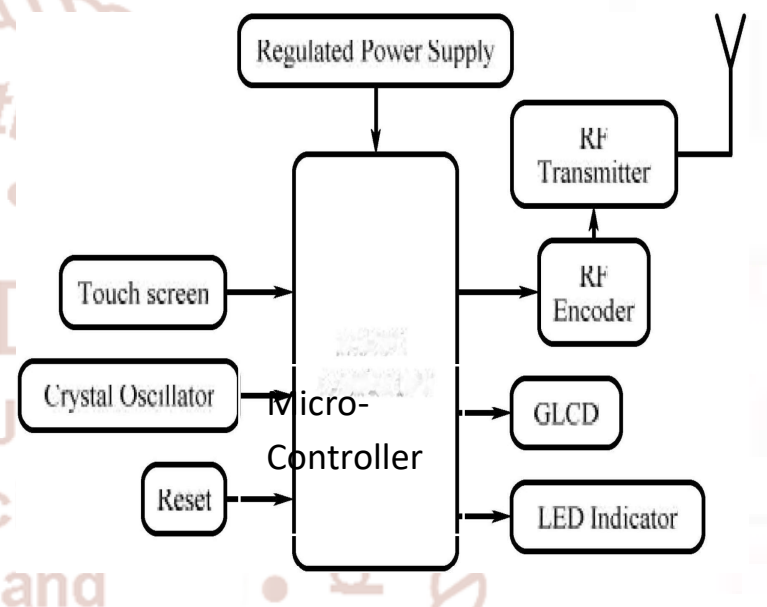

Fig. 6. Transmitter block diagram

\section{(b) Receiver Block:}

The Receiver Block is also made up of same components as of Transmitter. Here the input module consists of the Receiver module, which receives the order. The processing is done by the Micro-Controller and order will be placed. Once order is placed, the ordered food items will be shown on both of the screens, i.e. output display of Receiver Block as well as the input display of Transmitter Block.

The Touch-screen used is the GLCD, which is a Graphical LCD. Its a touch sensitive screen and supports $128 * 64$ pixels. The Micro-Controller used is Atmega 16. Its a 40 pin IC, it was selected for its qualities being cheap and reliable 


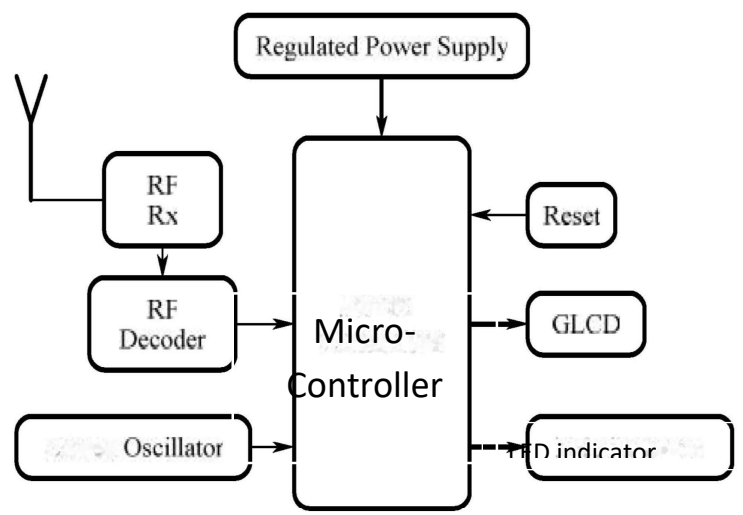

Fig. 7. Receiver block diagram

\section{ACKNOLEDGEMENT:-}

We would like to show our gratitude to the $\mathrm{Mr}$ Jayanth C Assistant Professor Department of Telecommunication, DSCE, Bangalore for sharing their pearls of wisdom with us during the course of this research.

\section{REFERENCES}

1) Mahesh G, Jayahari KR, and Kamal Bijlani, "A Smart Phone Integrated Smart Classroom," 2016 10th International Conference on Next Generation Mobile Applications, Security and Technologies, Cardiff, UK, pp. 88-93, 2016.

2) Wei Hsun Lee, Ming Chieh Kuo, Chung Chieh Hsu, "An In-classroom Interactive Learning Platform by Near Field Communication", 2015 8th International Conference on Ubi-Media Computing (UMEDIA): pp. 360 - 364, 2015.

3) Ramesh Guntha, Balaji Hariharan, P. Venkat Rangan, "Analysis of Echo Cancellation Techniques in Multi Perspective Smart Classroom," Advances in Computing, Communications and Informatics (ICACCI), 2016 International Conference on November 2016, Jaipur, India, pp.1134-1140, 2016.

4) Hichem Bargaoui, Rawia Bdiwi, "Smart classroom: Design of a gateway for ubiquitous classroom", 2014 International Conference on Web and Open Access to Learning (ICWOAL), pp. $1-4,2014$.

5) Raviprakash Shriwas ,Nikesh Patel, Asif Bherani, Arti Khajone, Manish Raut, "Touchscreen Based Ordering System For Restaurants", International Conference on Communication and Signal Processing, April 3-5, 2014, India, 2014.
6) MaoshengWu,XimengWu, "Design and Development of Multimedia Classroom Automation Management System”- IEEE 2011

7) Rozalind G. Muir-Herzig*, "Technology and its impact in the classroom", Pergamon Computers and Education 42 (2004) 111-131 Elsevier.

8) Mariluz Guenaga, Iratxe Mentxaka, Andoni Eguíluz, Susana Romero, Javier García Zubía, "Smartphones and teenagers, threat or opportunity" - IEEE 2012.

9) Lim Ean Heng, Anbuselvan Sangodiah, Wan Fatimah Bt. Wan Ahmad: 'End User's Perspective of Usability in Mobile Learning System"- 2012 International Conference on Computer \& Information Science (ICCIS).

10) Dr. Devesh Kumar Srivastava, Rishi Mathur, "Innovation and Technology in Engineering Education System based on Android"- IEEE 2013.

11) W. H. Lee and M. C. Kuo, "An NFC E-Learning Platform for Interactive and Ubiquitous Learning," in 2014 International Conference on Education Reform and Modern Management (ERMM-14), 2014. 